\title{
Mechanical Properties of Translucent Concrete Using Plexiglass Bars and Fiberglass
}

\author{
Walid Fouad Edris ${ }^{1,2, *}$, Essam Odah ${ }^{3,4}$, Isam Abu-Qasmieh $^{5}$, Amany Hendy ${ }^{6}$ \\ ${ }^{\mathbf{1} D e p a r t m e n t ~ o f ~ C i v i l ~ E n g i n e e r i n g, ~ H i j j a w i ~ F a c u l t y ~ f o r ~ E n g i n e e r i n g ~ T e c h n o l o g y, ~ Y a r m o u k ~ U n i v e r s i t y, ~ I r b i d, ~ 21163, ~ J o r d a n ~}$ \\ ${ }^{2}$ Department of Civil Engineering, Giza High Institute of Engineering and Technology, Awel Misr Assiut El Zeraay Rd., El Monib - \\ Giza, Egypt \\ ${ }^{3}$ Department of Industrial Design, Faculty of Applied Design, Helwan University, Egypt \\ ${ }^{4}$ Department of Architecture Engineering, Hijjawi Faculty for Engineering Technology, Yarmouk University, Irbid 21163, Jordan \\ ${ }^{5}$ Department of Biomedical Systems and Informatics Engineering, Hijjawi Faculty for Engineering Technology, Yarmouk University, \\ Irbid 21163, Jordan \\ ${ }^{6}$ Department of Interior Design \& Furniture, Faculty of Applied Design, Damietta University, Egypt
}

Received November 13, 2020; Revised January 20, 2021; Accepted January 28, 2021

\section{Cite This Paper in the following Citation Styles}

(a): [1] Walid Fouad Edris, Essam Odah, Isam Abu-Qasmieh, Amany Hendy, "Mechanical Properties of Translucent Concrete Using Plexiglass Bars and Fiberglass," Civil Engineering and Architecture, Vol. 9, No. 2, pp. 293 - 300, 2021. DOI: 10.13189/cea.2021.090203.

(b): Walid Fouad Edris, Essam Odah, Isam Abu-Qasmieh, Amany Hendy (2021). Mechanical Properties of Translucent Concrete Using Plexiglass Bars and Fiberglass. Civil Engineering and Architecture, 9(2), 293 - 300. DOI: 10.13189/cea.2021.090203.

Copyright $\odot 2021$ by authors, all rights reserved. Authors agree that this article remains permanently open access under the terms of the Creative Commons Attribution License 4.0 International License

\begin{abstract}
This research aims to investigate the efficiency of using plexiglass material as an alternative to optical fibers in the production of transparent concrete through studying the mechanical properties of transparent cement mortar. The importance of the current study comes to introduce innovative structural material with high aesthetic and structural specifications and meets the needs of the new concepts of sustainable buildings as well. The novelty of the proposed material lies in innovating a new type of transparent concrete using plexiglass material that allows light to cross through different directions, where such a polymer material can be embedded into the concrete as well-designed distributed bars. The proposed composite performance was evaluated by conducting relevant laboratory experiments on prepared mortar specimens to investigate compressive strength, flexural strength, and bond strength. The plexiglass bars were represented $6 \%$ and $16 \%$ of the specimen cross-section area, and volume respectively. Experiments were conducted in two time stages, after 7 days and after 28 days of preparing the mortar with plexiglass and fiberglass. Results show that the composite does not harm the mechanical specifications comparing with the conventional mortar, and obtaining new features of concrete with an emphasis on consistency to the requirements of
\end{abstract}

environmental sustainability in the field of architectural construction.

Keywords Translucent Concrete, Plexiglass, Mortar, Compressive Strength, Architectural Designs

\section{Introduction}

Recently, the search for methods and techniques to reduce energy consumption, reduce environmental pollution and minimize construction costs has become necessary. Currently, transparent concrete (TC) focuses on green technology and is characterized as being a potentially sustainable material.

Transparent concrete innovation was initiated in 1935 and was registered as a patent in Canada which was later improved by adding optical fiberglass [1]. In 1965 James N. Lowe from Britain introduced concrete wall panels that allow the light to penetrate using pieces of stained glass with the concrete mix and was applied to churches walls to allow light to cross into the building [2]. In 2001 a new concept of transparent concrete was introduced by Aron Losonzi as a patent where he innovated a new type of 
concrete known as LiTraCon by mixing a large amount of optical fiber with concrete and the composite was characterized to be produced as a rigid and transparent block and suitable for floors, sidewalks and load-bearing walls [3].

Accordingly, the importance of the current research is to study transparent concrete using plexiglass. Plexiglass material provides high transparency level as well as the ability to transmit light and color in straight and curved lines without affecting the level of transparency. Moreover, its low cost and availability makes it an adequate material for producing transparent concrete.

\section{1. literature Review}

Many types of research [4-8] have discussed the creation of different types of transparent concrete, depending on using optical fiber raw material. Multiple techniques have been suggested, either adding optical fiber dispersedly or in the form of bundles placed inside glass tubes. As a result, those optical fibers are soft and cannot be directly embedded in the concrete mixture; they are placed in tubes so that they can be included in the concrete mixture to achieve transparent concrete technology. This type of concrete is difficult to be applied practically due to the high costs of optical fibers, the difficulty of forming them inside the concrete panels, and the delicacy of the optical fiber diameters, which are measured by micron. As a result of these limitations, some researchers used materials that are easy to apply and inexpensive such as waste glasses [9, 10], glass rods [11], and epoxy resin rods [12] in LiTraCon. In 2010 a new type of transparent concrete was innovated by mixing glass with concrete in different amounts to focus more on transparency so it can be applied in green architecture [13]. Reference [14] the authors have used transparent plastic bars with diameter $5 \mathrm{~mm}$ and $10 \mathrm{~mm}$ to transmit light to the concrete with polyvinyl alcohol addition to overcome the problem of bonding between concrete and plastic bars, the arrested cracking, and the enhanced ductility [14-18]. The results showed that the insertion of the plastic bars reduced the concrete matrix-fiber transfer capacity [14]. Acrylic pipes and rods with diameters 3, 4, and $10 \mathrm{~mm}$ were used in lightweight aggregate concrete and lightweight foaming concrete [19]. The authors applied 10 $\mathrm{mm}$ steel fibers to $0.5 \%$ of the overall volume and the result showed that the compressive strength of lightweight aggregate concrete and lightweight foaming concrete decreased by $60 \%$ and $85 \%$ respectively. Most experimental works demonstrated there was a reduction in mechanical properties with an increasing optical fiber content of LiTraCon [11, 12,20, and 21]. Due to the difficulties of compaction concrete in presence of optical fibers, some authors prefer to investigate translucent cement mortar. [20-22] showed that the translucent cement mortar is more efficient than the translucent concrete.

The current research proposes the possibility of taking advantage of the optical and mechanical properties of the plexiglass material to be used as an alternative to optical fibers in the production of transparent cement mortar. Furthermore, the possibility of re-using pre-fabricated and used plexiglass raw materials that can be cut by laser in the form of bars of equal lengths which are then included in the concrete mix to make it transparent and therefore, achieves the concept of environmental sustainability in producing this type of concrete by avoiding the recycling of this polymer which polluting the environment. The paper proceeds by display the applications of transparent concrete. Afterward, the properties of used materials along with the utilized methodology are introduced. Then, results analysis is illustrated. Finally, the conclusion is presented.

\section{Applications}

Various applications of adding plexiglass bars with fiberglass in cement mix are listed and discussed as follows:

- Transparent concrete using plexiglass bars can be employed in the architectural facades as shown in Fig. 1A, interior sectors as shown in Fig. 1B, tourist camps as shown in Fig.1C, and roofs as shown in Fig.1D.

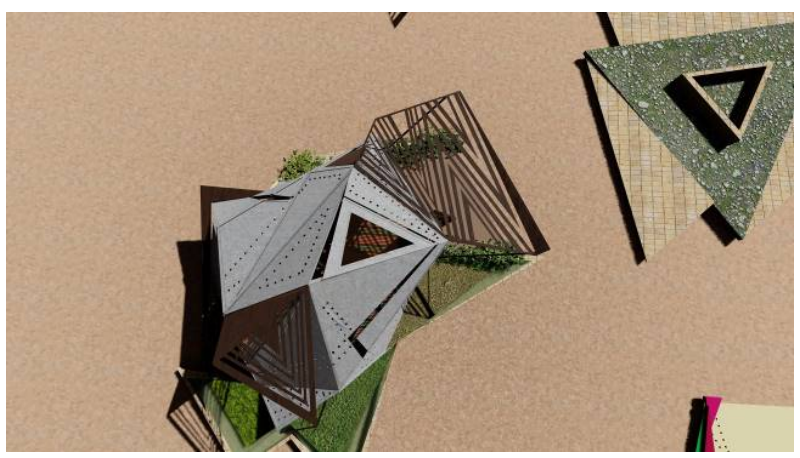

(A)

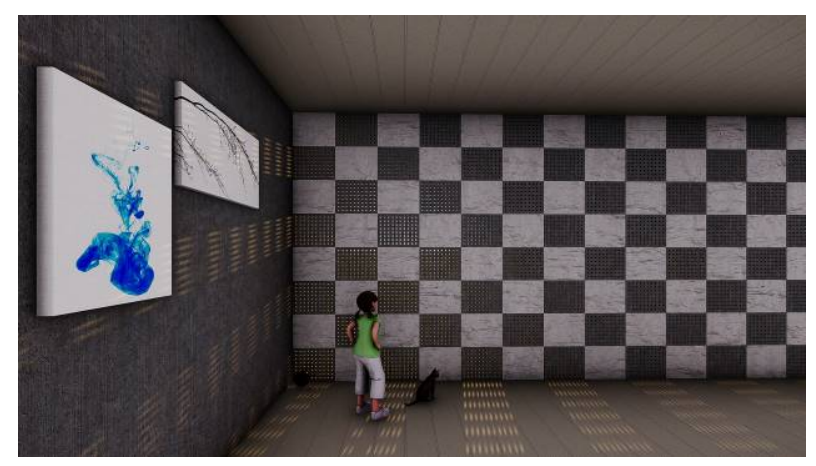

(B) 


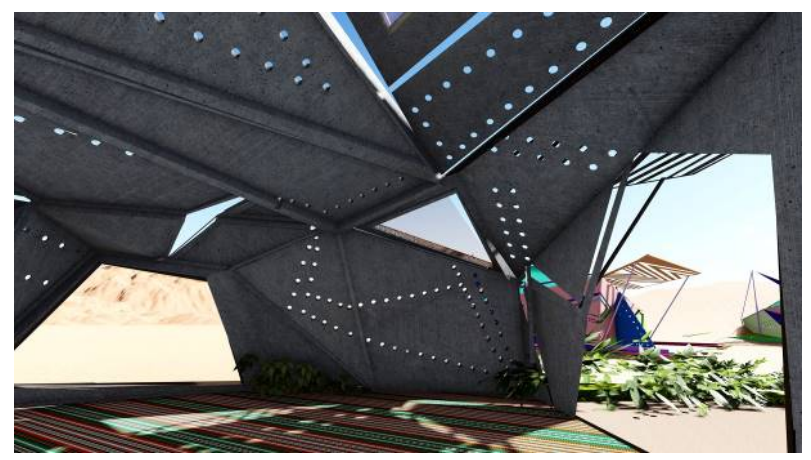

(C)

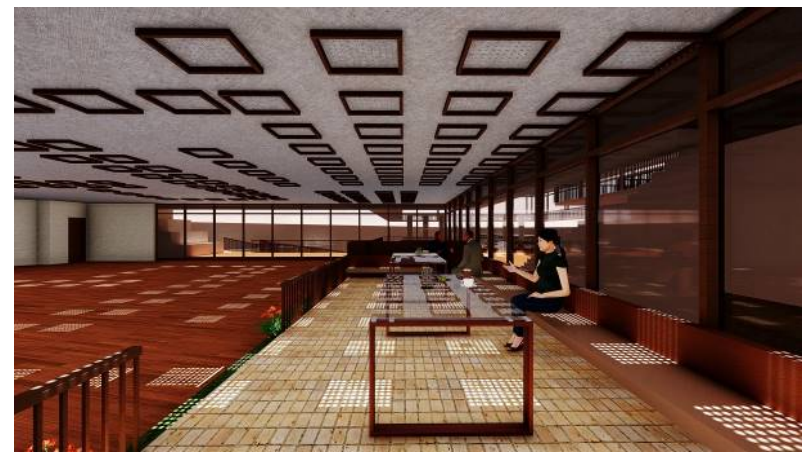

(D)

Figure 1. A,B,C,D. Various applications of adding plexiglass bars in concrete

A high level of transparency in the proposed composite can be used to illuminate the interior space of the building by employing the surrounding natural lighting as shown in figure 2 .

An interactive architectural space can be created using transparent concrete slabs due to the advantage of plexiglass raw material in its ability to transfer colors from one side to another in straight or curved lines, thus the motion effect within the architectural space is transferred to the outside and vice versa as shown in figure 3.

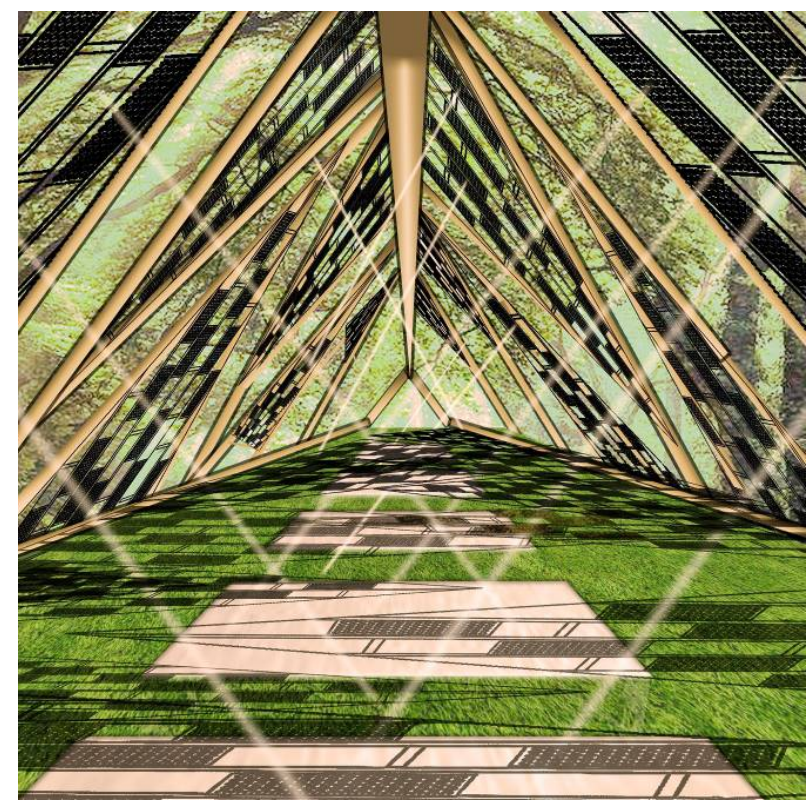

Figure 2. Example of a high level of transparency

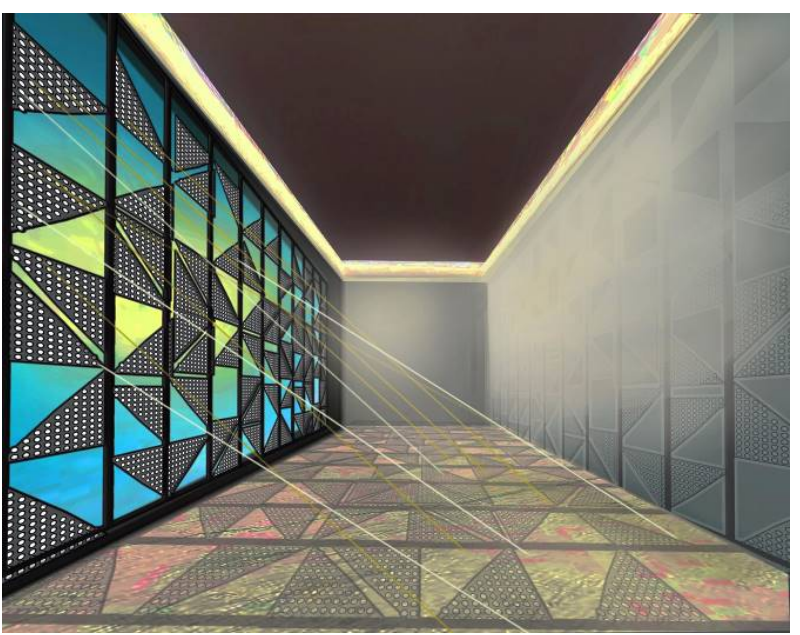

Figure 3. The ability of Transparent concrete to transfer colors from one side to another 


\section{Materials and Methods}

\subsection{Materials}

The cement used in this study is Portland Pozzolan cement, namely, Type II / P - P 42.5 N (JS 30-102007). The chemical compositions of the cement are presented in Table 1 . The sand used for the research work was locally procured and conformed to standard specification ASTM C778 [23]. The size of the sand particles is passed through sieve \#4 (4.75 mm) and retained on sieve \#200 (0.075 $\mathrm{mm})$. Figure 4 shows a fine grading size distribution.

Table 1. Chemical composition of the cement used

\begin{tabular}{|c|c|}
\hline Oxides (\%) & CEM II/P-P 42.5 N \\
\hline $\mathrm{SiO} 2$ & 19.07 \\
\hline $\mathrm{Al} 2 \mathrm{O} 3$ & 2.39 \\
\hline $\mathrm{Fe} 2 \mathrm{O} 3$ & 9.52 \\
\hline $\mathrm{CaO}$ & 63.24 \\
\hline $\mathrm{MgO}$ & ---- \\
\hline $\mathrm{Na} 2 \mathrm{O}$ & 0.014 \\
\hline $\mathrm{K} 2 \mathrm{O}$ & 0.18 \\
\hline $\mathrm{SO} 3$ & 2.47 \\
\hline
\end{tabular}

The various other tests conducted are specific Gravity, bulk density, fineness modulus, water absorption, and sieve analysis, where the results are listed in Table 2.

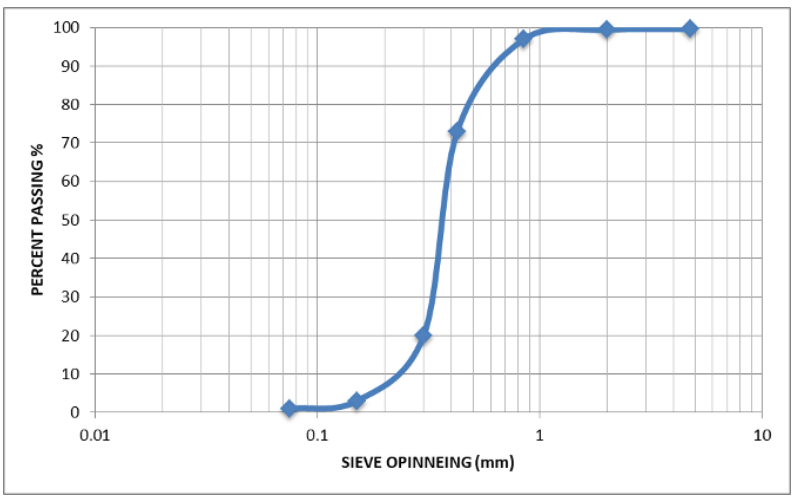

Figure 4. Aggregate grading size distribution

Table 2. Physical properties of fine aggregate

\begin{tabular}{|c|c|}
\hline Aggregate type & CEM II/P-P $42.5 \mathrm{~N}$ \\
\hline $\mathrm{D} \max$ & ------ \\
\hline Specific Gravity(Dry) & 2.28 \\
\hline Specific Gravity(SSD) & 2.41 \\
\hline Bulk Density $\left(\mathrm{Kg} / \mathrm{m}^{3}\right)$ & ----- \\
\hline Absorption \% & 5.59 \\
\hline F.M* & 2.9 \\
\hline \multirow[t]{2}{*}{ MC* \% } & 3.73 \\
\hline & 2.47 \\
\hline
\end{tabular}

Glass fiber with an average length of $(40 \mathrm{~mm})$ was added manually in different percentages $2.5 \%$ and $3.75 \%$ during the mixing process. Plexiglass bars are an amorphous thermoplastic compound that is optically transparent, unaffected by moisture, offers a high strength-to-weight ratio, good weather stability, and resistance to prolonged sunlight exposure. Glass fiber and Plexiglass bar with a diameter of $6 \mathrm{~mm}$ were used in this study shown in figure 5 .

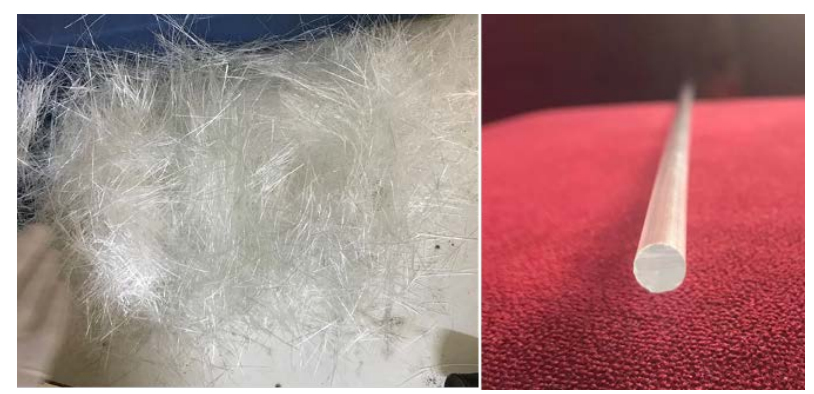

Figure 5. Detailed images of glass fiber and Plexiglass bars.

\subsection{Methodology}

Different mix proportions were designed to study the impact of plexiglass on cement mortar behavior besides the control mix that was prepared without plexiglass. Plexiglass bar with diameter $6 \mathrm{~mm}$ with fine cement mortar mix ratio is $1: 2.75$ and the water-cement ratio is 0.485 . Also, to improve the properties of the innovative concrete matrix, fiberglass with $2.5 \%$ and $3.75 \%$ were added to the cement mix to overcome the weak bonds between the concrete mixture and the smooth surface of the plexiglass bars. Some mixes were prepared as a control mix to compare the mechanical properties of cement using $100 \%$ Portland cement with glass fiber addition and without adding plexiglass bars. Preparation of the plexiglass bars in the mold is carried out by well-designed holes, arranged in orthogonal arrays prepared by drilling a Formica wood sheet using a CNC machine. The plexiglass bars are then fixed in the slots so that they are completely arranged and aligned as shown in Figure 6. The addition of the plexiglass bars represents $6 \%$ and $16 \%$ of the specimen cross-section area, and volume respectively. Next, the mortar was placed into molds by three layers where each layer is compacted properly. After molding, the specimens were left at room temperature 23C for 24h, and then, the specimens of both mortars were demolded and kept in a curing tank for the respective periods of 7 and 28 days. A set of 3 specimens were prepared for each stage of curing. To obtain a highly-smooth surface, plexiglass bars were cut and the surfaces of both sides were polished. Figure 7 summarizes the experimental methodology of this study. 

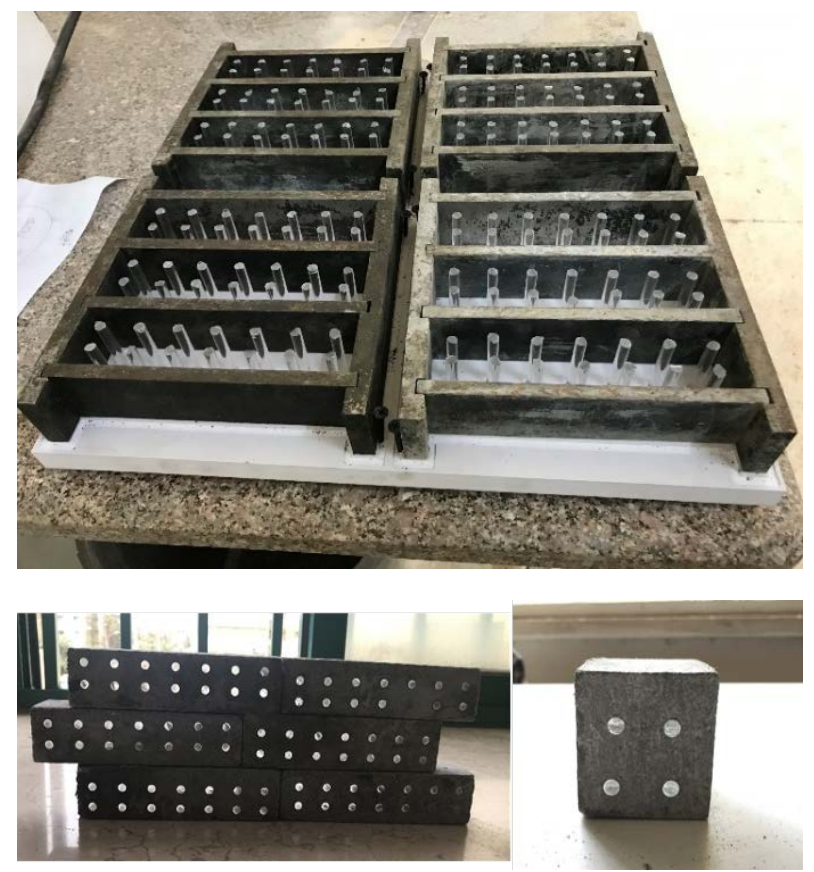

Figure 6. Specimens prepared for compression and flexural tests

For all mixes, the compression, flexural, and pull-out tests using the standards of ASTM were performed. The Blended cement mortar was prepared using the required water/binder ratio following ASTM C305 [24].

For the flexural test, a sample of three prismatic specimens of $40 \times 40 \times 160 \mathrm{~mm}$ was used according to ASTM C348 [25] for the different replacement percentages.
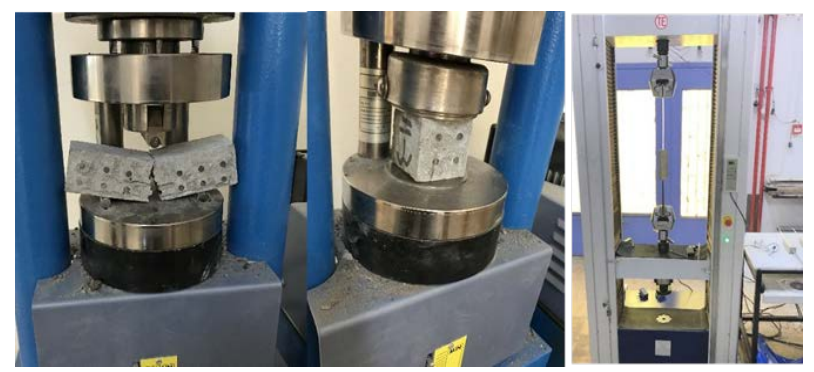

Figure 7. Setup of compression, flexural and pull out tests

For the compression test, a set of three cubic specimens of mortar and curing time were used for the determination of compressive strength according to ASTM C-109[26]. The specimens were cast in molds of size $(50 \times 50 \times 50 \mathrm{~mm})$. Pull out the test, is the resistance of mortar to the adhesion of the plexiglass bars reinforcement within it. The determination of the cohesion resistance between the mortar and the plexiglass bars is carried out by determining the load that causing the collapse and sliding of the plexiglass bars inside the mortar. The test specimen is three prismatic specimens of size $40 \times 40 \times 160 \mathrm{~mm}$ was used, providing that the plexiglass bars have to be tested in its center, and from the other end of the specimen, a steel bar has been installed so that we can install the specimen in the platens of the testing machine. The plexiglass bars are pulled by the bearing end gradually, causing the bearing to slip. The load-and-slide readings of the bearing end determine the $0.25 \mathrm{~mm}$ load-bearing load. And based on this, resistance cohesion is the slipping load divided by the area of plexiglass bars that adheres to mortar.

\section{Results and Discussion}

\subsection{Compressive Strength}

Cube specimens of mortar were prepared to conduct the compressive strength test according to ASTM C-109. The test was established as a method for determining the 7 and 28 days' compressive strengths. The obtained results are shown in Figure 8 and Table 3.

Table 3. Compressive strength results

\begin{tabular}{|c|c|c|c|c|c|}
\hline Mi & \multirow{2}{*}{$\begin{array}{c}\% \\
\mathrm{x}\end{array}$} & $\begin{array}{c}\text { of glass } \\
\text { fiber }\end{array}$ & plexiglass bars & Density & \multicolumn{2}{|c|}{$\begin{array}{c}\text { Compressive } \\
\text { strength } \\
\text { (MPa) }\end{array}$} \\
\cline { 5 - 6 } & & $(\mathrm{Kg} / \mathrm{cm} 3)$ & $\begin{array}{c}7 \\
\text { days }\end{array}$ & $\begin{array}{c}28 \\
\text { days }\end{array}$ \\
\hline 1 & 2.5 & Without plexiglass & 2324 & 20.4 & 23.7 \\
\hline 2 & 2.5 & $\begin{array}{c}\text { 4 bars with a } \\
\text { diameter of } 6 \mathrm{~mm} \\
\text { and height of } 50 \\
\text { mm in each cube }\end{array}$ & 2094 & 24.3 & 32.7 \\
\hline 3 & 3.75 & $\begin{array}{c}\text { 4 bars with } \\
\text { diameter 6 mm and } \\
\text { height } 50 \mathrm{~mm} \text { in } \\
\text { each cube }\end{array}$ & 2045 & 21.6 & 27.0 \\
\hline
\end{tabular}

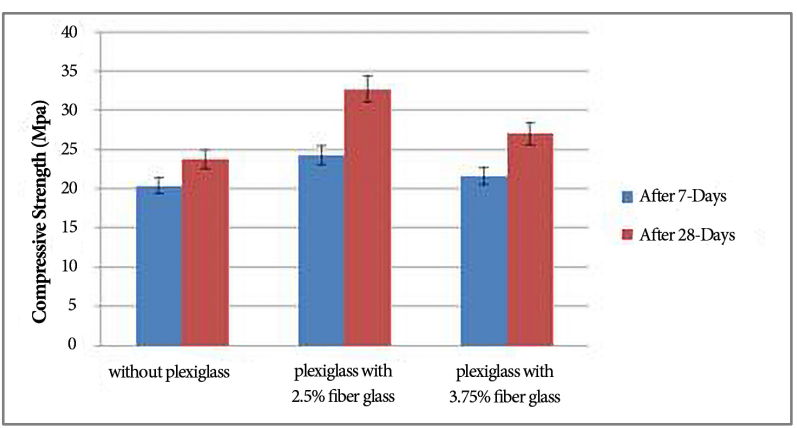

Figure 8. Results of a compression test

The results are shown in Table 3 and the Figure 8 indicated that the compression resistance for specimens that do not contain plexiglass bars and with the percentage of fiber $2.5 \%$ has the least resistance, whether after 7 days or 28 days. The results also show that the specimens containing plexiglass and with the ratio of $2.5 \%$ fibers achieved the highest resistance. It is also noted that the samples that contain the same plexiglass bars, but with a fiber ratio of $3.75 \%$ have a higher resistance than that which does not have plexiglass bars and less than the specimens that have the same plexiglass bars percentage, 
but with the $2.5 \%$ percentage of fiber. It is obvious from the obtained results that the plexiglass bars and the fiber, with different ratios, have no significant effect on the compressive strength. Also, using the plexiglass bars with the concrete mix will reduce the concrete density and consequently its total weight.
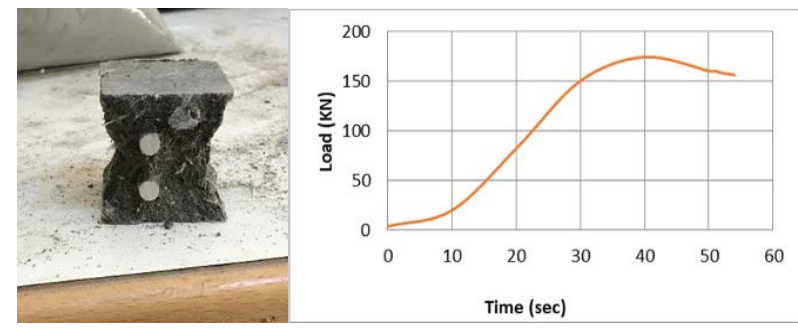

Figure 9. A typical compression test illustrates the failure due to shear stress

Figure 9. shows that the fracture resulting from specimens that contain plexiglass bars is a typical failure due to shear stress resulting from friction of the surface of the specimen and the machine platens, which is similar in standard samples that do not contain plexiglass.

\subsection{Flexural Strength}

The impact of adding the fiber on the resistance to flexural is shown clearly in Figure 10. and Table 4. Specimens that contain plexiglass bars and fiber of 3.75\% percentage provide higher resistance than specimens with a fiber of $2.5 \%$. This is because the modulus of fiber elasticity is high, and also it works to close the micro-cracks during loading, which helps to improve the flexural properties of the cement mortar. Figure 11 shows the cross-sections of the specimens after the flexural test.

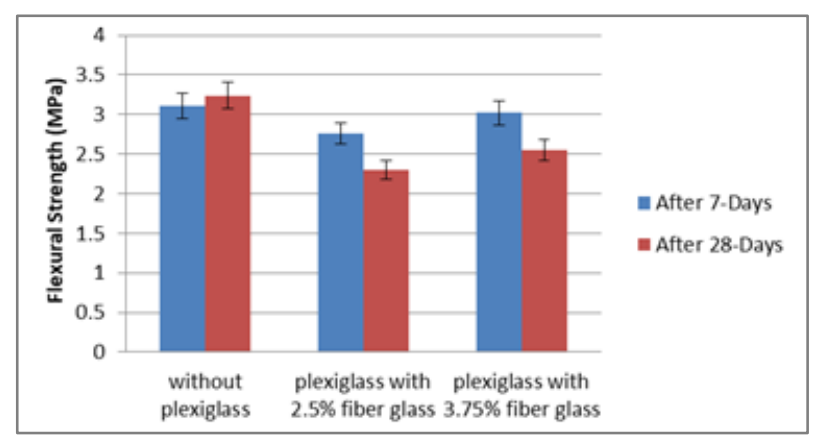

Figure 10. Flexural strength results.

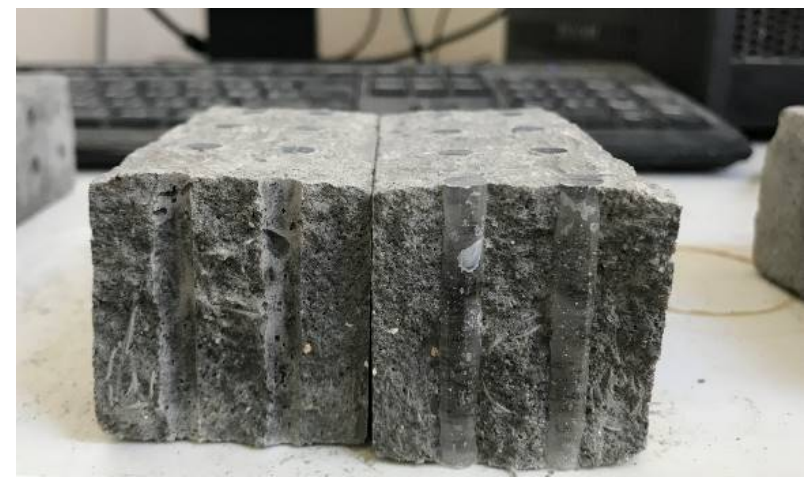

Figure 11. Cross-sections of flexural test specimens

Improving the concrete compressive strength, flexural strength, and pullout resistance will qualify it to be widely used in roads, pathways, and playgrounds which are exposed to heavy use by pedestrians and vehicles. Also, adding the plexiglass bars to the concrete ingredients will reduce the porosity of the concrete surface, and therefore, the permeability of water is reduced, which limits the reproduction of algae on the concrete surface.

Table 4. Flexural strength results

\begin{tabular}{|c|c|c|c|c|c|}
\hline \multirow{2}{*}{ Mix No. } & $\begin{array}{c}\% \\
\text { of glass fiber }\end{array}$ & plexiglass bars & \multirow{2}{*}{$\begin{array}{c}\text { Density } \\
(\mathrm{Kg} / \mathrm{cm} 3)\end{array}$} & \multicolumn{2}{|c|}{ Flexural strength (MPa) } \\
\cline { 4 - 6 } & 2.5 & Without plexiglass & 2258 & 3.11 & 3.24 \\
\hline 1 & 2.5 & $\begin{array}{c}14 \text { bars with diameter 6 mm and } \\
\text { height 40 mm in each cube }\end{array}$ & 2133 & 2.76 & 2.30 \\
\hline 3 & 3.75 & $\begin{array}{c}14 \text { bars with diameter 6 mm and } \\
\text { height 40 mm in each cube }\end{array}$ & 1976 & 3.02 & 2.55 \\
\hline
\end{tabular}




\subsection{Bond Strength}

The bond resistance depends on both the properties of mortar and plexiglass bars properties, as well as the contact area between them. The resistance to cohesion is greater in the case of bars with protrusions than in the case of smooth bars. According to the pull-out test, the bond strength is $1.23 \mathrm{~kg} \backslash \mathrm{cm}^{2}$.

The bonds weakness between the concrete mix and the plexiglass bars are assumed to contribute significantly in limiting the impact of atmospheric turbulence, sandy winds, and fires, without affecting the conventional concrete structure properties, but on the other hand, it will reduce the chances of disposing of the concrete blocks in the surrounding environment.

\section{Conclusions}

Transparent cement mortar using plexiglass bars is an improved GRC material and can be obtained by implanting transparent bars of plexiglass and characterized by its ability to transmit light in straight lines. The current research work assumes that transparent concrete using plexiglass material innovative structure can be implemented in several architectural and structural purposes such as the architectural facades, floors, ceilings, partitions, ... etc, to achieve an interactive architectural environment. Moreover, the use of plexiglass raw material in the production of transparent concrete reduces costs considerably compared to the use of high-cost optical fibers, besides the re-use of plexiglass bars and the ability to manufacture the plexiglass raw material locally using at-hand technology. Furthermore, results show that the translucent cement mortar does not harm the mechanical specifications comparing with the conventional mortar. Besides, the use of plexiglass bars improves the concrete thermal specifications due to their poor thermal conductivity and due to the easiness of performing regular maintenance to the plexiglass bars by polishing their apparent cross-sections to ensure their transparent quality. Also, such a structure will reduce the concrete density and therefore its weight. Because of the low adhesive binding affinity of the conventional concrete structure with the plexiglass bars, fiberglass substance was added with different percentages to improve the concrete resistance against cracking and consequently improving its mechanical specifications and achieving higher safety performance.

\section{Acknowledgments}

We are very grateful to the Yarmouk University and Giza High Institute of Engineering and Technology for their appropriate and constructive suggestions to support the data of this study.

\section{REFERENCES}

[1] OnlineAvailable:https://en.wikipedia.org/wiki/Translucent_ concrete\#cite_note_pat_de_1986-10, June 2018.

[2] Hiren B. Valambhiya, Tushar J. Tuvar, Pankaj V. Rayjada "history, and case study on light-transmitting concrete". JETIR1701004, 2017.

[3] Kashiyani, B. K., Raina, V., Pitroda, J., and Shah, B. K., “A Study on Transparent Concrete: A Novel Architectural Material to Explore Construction Sector," Engineering and Innovative Technology (IJEIT), Vol. 2, No. 8, pp. 83, 2013.

[4] Awetehagn Tuaum, Stanley Muse Shitote and Walter Odhiambo Oyawa "Experimental Evaluation on Light Transmittance Performance of Translucent Concrete”. International Journal of Applied Engineering Research ISSN 0973-4562 Volume 13, Number 2 pp. 1209-1218, 2018.

[5] Karthika. K, Gayathri R.K, Isaiselvi. M, Hemapriya. S "experimental investigation on translucent concrete". International journal of innovative research in technology. IJIRT, Volume 5 Issue 10 | ISSN: 2349-6002, 2019.

[6] Shakir Ahmed Salih, Hasan Hamodi Joni, Safaa AdnanMohamed. "Effect of Plastic Optical Fiber on Some Properties of Translucent. Concrete”. Eng. \&Tech. Journal, Vol. 32, Part (A), No.12, 2014.

[7] Riya Gite, Shilpa Kewate "Critical study on Transparent Concrete”. International Journal of Scientific \& Engineering Research, Volume 8, Issue 3, March-2017.

[8] Shwan H. Said. State-of-the-art developments in light-transmitting concrete. Materials Today: Proceedings, 2020.

[9] P. Spiesz, S. Rouvas, H.J.H. Brouwers, Utilization of waste glass in translucent and photocatalytic concrete, Constr. Build. Mater. 128, 436-448, 2016.

[10] S.L. Pagliolico, V.R.M.L. Verso, A. Torta, M. Giraud, F. Canonico, L. Ligi, A preliminary study on light transmittance properties of translucent concrete panels with coarse waste glass inclusions, in $\mathrm{M}$. Perino, V. Corrado (Eds.), 6th International Building Physics Conference, (IBPC), ScienceDirect, Italy Torino. pp. 1811-1816, 2015.

[11] S.M. Kankriya, Translucent concrete by using optical fibers and glass rods, Int.J. Sci. Res. Publ. 6 (10), 625-627, 2016.

[12] R. Mohan, P. Tyagi, R. Sharma, H. Rajan, Experimental studies on POF and epoxy-resin based translucent concrete, Int. J. Latest Technol. Eng. Manage. Appl. Sci. (IJLTEMAS) 7 (3) ,130-134, 2018.

[13] Amira Saody, "Experimental Concept Design using Transparent Concrete Technology in Interior Architecture” Conference on Innovation in Heritage Industries.

[14] Byoungil Kim and Yoon-Jung Han "Flexural Performance of Transparent Plastic Bar Reinforced Concrete". Applied Sciences Journal, Volume 8, Issue 3, 325; https://doi.org/10 .3390/app8030325. 2018

[15] Gayathri, K.S.; Anand, K.B. Performance evaluation of 
PVA fiber reinforced concrete. Indian Concr. J., 91, 30-36, 2017.

[16] Hamoush, S.; Abu-lebdeh, T.; Cummins, T. Deflection behavior of concrete beams reinforced with PVA micro-fibers. Constr. Build. Mater, 24, 2285-2293. [CrossRef]. 2010.

[17] Liu, R.M.; Liu, W. Effect of PVA fiber on flexural properties of high-performance concrete. Appl. Mech. Mater., 438-439, 262-265. [CrossRef]. 2013.

[18] Bauml, M.F.; Wittmann, F.H. Application of PVA-fiber reinforced self-compacting concrete (ECC) for repair of concrete structures. Restore. Build. Monument, 8, 591-604, 2002.

[19] B. Kim, Light transmitting lightweight concrete with transparent plastic bar, Open Civ. Eng. J. 11, 615-626, 2017

[20] H. Ashok, J. Ravindraraj, S. Ramesh, R. Ramkumar, Performance evaluation on light-transmitting concrete (translucent concrete), International Journal of Research, Eng. Technol. 5 (3), 515-521, 2016.

[21] A. Magesh, P. Abishek, M. Arunachalam, N. Karthikraj, K.B. Madhan, Performance evaluation of light-transmitting in M20 grade concrete, Int. J.Adv. Res. Innovate. Ideas Educ. (IJARIIE) 3 (3), 2798-2811, 2017.

[22] R. Pradheepa, S. Krishnamoorthi, Light Transmission of transparent concrete, Int. J. Sci. Eng. Res. 3 (4), 2015.

[23] ASTM C778 -17 Standard Specification for Standard Sand

[24] ASTM C305. Standard Practice for Mechanical Mixing of Hydraulic Cement Pastes and Mortars of Plastic Consistency.

[25] ASTM C348. Standard Test Method for Flexural Strength of Hydraulic-Cement Mortars

[26] ASTM C-109. Standard Test Method for Compressive Strength of Hydraulic Cement Mortars (Using 2-in. or [50-mm] Cube Specimens). 